\title{
Hemiptera infesting willow (Salix viminalis) plantations
}

\section{Pluskwiaki (Hemiptera) spotykane na plantacjach wierzby wiciowej (Salix viminalis)}

\author{
Danuta Wrzesińska, Maria Wawrzyniak, Dariusz Piesik
}

\section{Summary}

Over 2008-2009 in the Kujawy and Pomorze Province research was performed on the species composition, abundance and dominance of Hemiptera caterpillars feeding on common osier Salix viminalis. The results of the research revealed that the plants were infested by the bugsrepresenting 13 families: Aphididae, Aphrophoridae, Cicadellidae, Delphacidae, Acanthosomatidae, Anthocoridae, Beritidae, Coreidae, Lygaeidae, Miridae, Nabidae, Pentatomidae and Thyreocoridae. In the habitats investigated, the species Javesella pellucida Fab. and Aphis farinose Gmelin. were mostly represented.

Key words: Salix, Hemiptera, Javesella pellucida Fab., Aphis farinose Gmelin.

\section{Streszczenie}

W latach 2008-2009 na terenie województwa kujawsko-pomorskiego przeprowadzono badania nad składem gatunkowym, liczebnością i dominacją pluskwiaków (Hemiptera) spotykanych na wierzbie wiciowej Salix viminalis. Badania wykazały, że rośliny te zasiedlają pluskwiaki należące do 13 rodzin: Aphididae, Aphrophoridae, Cicadellidae, Delphacidae, Acanthosomatidae, Anthocoridae, Beritidae, Coreidae, Lygaeidae, Miridae, Nabidae, Pentatomidae i Thyreocoridae. W badanych siedliskach najliczniej notowano: Javesella pellucida Fab. i Aphis farinosa Gmelin.

Słowa kluczowe: wierzba, pluskwiaki, Javesella pellucida Fab., Aphis farinosa Gmelin.

\footnotetext{
Uniwersytet Technologiczno-Przyrodniczy im. Jana i Jędrzeja Śniadeckich w Bydgoszczy Katedra Entomologii i Fitopatologii Molekularnej

Kordeckiego 20, 85-225 Bydgoszcz

danuta@utp.edu.pl
} 


\section{Wstęp / Introduction}

Zmniejszające się zasoby konwencjonalnych surowców energetycznych powodują zainteresowanie się energią zgromadzoną w roślinach, w tym, w wierzbie wiciowej Salix viminalis. Zwiększony areał uprawy tej rośliny powoduje wzrost liczebności różnych gatunków owadów (Wrzesińska i Wawrzyniak 2011, 2012). Wśród nich licznie reprezentowaną grupą są pluskwiaki.

Celem badań było poznanie składu ilościowego pluskwiaków spotykanych na plantacjach $S$. viminalis, ich dominacji oraz preferencji pokarmowych.

\section{Materiały i metody / Materials and methods}

W latach 2008-2009 przeprowadzono badania na dwóch towarowych plantacjach wierzby wiciowej, usytuowanych w województwie kujawsko-pomorskim. Obiektem badań były pluskwiaki.

Próby do analiz pobierano systematycznie co 10-14 dni, od maja do października. Pluskwiaki odławiano każdorazowo z 10 krzewów przy pomocy czerpaka entomologicznego oraz pułapek Barbera. Na każdej powierzchni badawczej założono po 5 pułapek glebowych, które wypełnione były roztworem glikolu etylenowego. Pierwsze stanowisko w Dobrczu usytuowane było w pobliżu jeziora i otoczone rolniczym krajobrazem, drugie w Suponinie w pobliżu pól uprawnych, łąk, niewielkiego lasu i rowu melioracyjnego, obsadzonego drzewami liściastymi.

Zebrane owady przewożono do Katedry Entomologii Stosowanej Uniwersytetu Technologiczno-Przyrodniczego w Bydgoszczy. W laboratorium segregowano je i charakteryzowano pod względem ilościowym oraz oznaczano gatunki. Nazewnictwo owadów przyjęto za Fauna Europaea (2011).

W badaniach określono również dominację osobniczą (D), czyli procentowy udział danego gatunku w badanych stanowiskach (Kasprzak i Niedbała 1981). Dla opisowego przedstawienia wartości wskaźnika D przyjęto pięć klas dominacji: D5 - eudominanty - do których zaliczono gatunki najliczniejsze, zawierające ponad $10 \%$ osobników porównywanej grupy taksonomicznej, D4 - dominanty, czyli gatunki średnio liczebne zawierające od 5,1 do $10 \%$ osobników, D3 - subdominanty - od 2,1 do 5\%, D2 recedenty - od 1,1 do $2 \%$ i gatunki nieliczne D1 - subrecedenty - poniżej $1,1 \%$ osobników.

\section{Wyniki i dyskusja / Results and discussion}

W okresie dwóch sezonów wegetacyjnych zebrano 1541 pluskwiaków należących do 3 podrzędów: piersiodziobych (Sternorrhyncha), piewików (Auchenorhyncha) i pluskwiaków różnoskrzydłych (Heteroptera) oraz 13 rodzin: mszycowatych (Aphididae), pienikowatych (Aphrophoridae), skoczkowatych (Cicadellidae), szydlakowatych (Delphacidae), puklicowatych (Acanthosomatidae), dzióbałkowatych (Anthocoridae), smukleńcowatych (Beritidae), wtykowatych (Coreidae), zwińcowatych (Lygaeidae), tasznikowatych (Miridae), zażartkowatych (Nabidae), tarczówkowatych (Pentatomidae) i Thyreocoridae.

Najwięcej przedstawicieli rzędu Hemiptera stwierdzono w roku 2008 (61,19\%), mniej w roku 2009 $(38,81 \%)$. W ciagu dwóch lat badań na obu stanowiskach zebrano 37 gatunków pluskwiaków, w Dobrczu - 33, a w Suponinie - 30. Najwięcej gatunków odłowiono z rodziny Miridae (8) i Pentatomidae (5). We wszystkich stanowiskach najliczniej reprezentowana grupa pod względem ilościowym były fitofagi (28), natomiast mniej było zoofagów (8) (tab. 1). W Dobrczu zebrano 25 gatunków pluskwiaków roślinożernych, a w Suponinie - 22. Wśród pluskwiaków, na obu stanowiskach, znalazł się jeden gatunek o szerokim spektrum pokarmowym - Pentatoma rufipes. Jest to pluskwiak eurosyberyjski. Często oprócz roślin wysysa drobne owady, a czasem nawet jaja złożone przez samice własnego gatunku. W Polsce jest to gatunek pospolity na różnych gatunkach drzew (Lis 2000). W Dobrczu i Suponinie wystapił jednak nielicznie.

$\mathrm{W}$ tabeli 2. przedstawiono dominację osobniczą (D) owadów zasiedlających $S$. viminalis. W badanych stanowiskach najliczniej notowano skoczka trawnika Javesella pellucida i mszycę wierzbową pospolitą Aphis farinosa. Spośród ogółu zebranej Hemipterofauny skoczek trawnik stanowił w Suponinie 43,37\%, a w Dobrczu 40,92\%, natomiast mszyca wierzbowa $\mathrm{w}$ tych samych stanowiskach kolejno 20,03 i 22,36\%. Plantacje wierzby wiciowej zachwaszczone były trawami i chwastami, dlatego w pułapkach Barbera i próbach czerpakowych notowano licznie skoczka trawnika, szkodnika zbóż i traw. Gatunek ten w sezonie wegetacyjnym występował w dwu zazębiających się pokoleniach. Według Nowackiej (1996) skoczek trawnik jest wektorem wirusów płonnej karłowatości owsa oraz paskowanej mozaiki pszenicy. W związku z tym może stanowić źródło zagrożenia dla uprawianych w okolicy zbóż. Kolejny eudominant A. farinosa jest mszycą jednodomna, holocykliczną, szeroko rozpowszechnioną w świecie. Na końcach młodych pędów wierzby takson ten tworzył zwarte kolonie złożone $\mathrm{z}$ larw i licznych bezskrzydłych samic, które wysysały soki z liści przyczyniając się do ich deformacji i ograniczenia fotosyntezy. Według Tomczyk (2008) mszyce żerujące na wierzbach są poważnymi konsumentami asymilatów, a ich żerowanie doprowadza do ograniczenia wzrostu roślin. Liście, na których żerowały mszyce były drobne.

Wśród dominantów w Dobrczu zanotowano fitofagicznego przedstawiciela $\mathrm{z}$ rodziny Thyreocoridae Thyreocoris scarabaeoides, a w Suponinie zmiennika lucernowca Lygus rugulipennis, należącego do rodziny tasznikowatych. T. scarabaeoides charakteryzował się masywnym, wypukłym ciałem, silnie rozwiniętą tarczką, zakrywającą część odwłoka oraz 3-członowymi odnóżami. Dorosłe osobniki tego gatunku, ze względu na specyficzny tryb życia (na ziemi lub u nasady łodyg) odławiano tylko w pułapkach Barbera. Na plantacji wierzby wiciowej w Dobrczu odżywiał się różnymi roślinami dwuliściennymi rosnącymi pod krzewami. Jego larwy są typowymi monofagami żyjącymi wyłącznie na fiołku trójbarwnym (Lis 1997). Szkodnik ten ma jedno pokolenie w roku i zimuje w postaci imago. W drugim stanowisku dominujący pluskwiak zmiennik lucernowiec zaliczany jest do 
Tabela 1. Pluskwiaki zasiedlające wierzbę energetyczną $S$. viminalis

Table 1. Hemiptera of common osier $S$. viminalis

\begin{tabular}{|c|c|c|c|c|c|c|}
\hline \multirow{3}{*}{$\begin{array}{l}\text { Lp. } \\
\text { No. }\end{array}$} & \multirow{3}{*}{$\begin{array}{l}\text { Rodzina - Gatunek } \\
\text { Family - Species }\end{array}$} & \multicolumn{4}{|c|}{ Stanowiska - Localisation } & \multirow{3}{*}{$\begin{array}{c}\text { Specjalizacja } \\
\text { pokarmowa } \\
\text { Food specialization }\end{array}$} \\
\hline & & \multicolumn{2}{|c|}{ Dobrcz } & \multicolumn{2}{|c|}{ Suponin } & \\
\hline & & 2008 & 2009 & 2008 & 2009 & \\
\hline 1 & 2 & 3 & 4 & 5 & 6 & 7 \\
\hline A. & Piersiodziobe - Sternorrhyncha & & & & & \\
\hline $\mathrm{I}$ & Mszycowate - Aphididae & & & & & \\
\hline 1. & $\begin{array}{l}\text { Mszyca wierzbowa pospolita } \\
\text { Aphis farinosa Gmelin, } 1790\end{array}$ & + & + & + & + & $\mathrm{F}$ \\
\hline 2. & $\begin{array}{l}\text { Mszyca wierzbowo-marchwiana } \\
\text { Cavariella aegopodii Scopoli, } 1758\end{array}$ & + & + & + & + & $\mathrm{F}$ \\
\hline 3. & C. pastinacae Linnaeus, 1758 & + & + & + & + & F \\
\hline B. & Piewiki - Auchenorhyncha & & & & & \\
\hline II. & Pienikowate - Aphrophoridae & & & & & \\
\hline 4. & $\begin{array}{l}\text { Pienik olchowiec } \\
\text { Aphrophora alni Fallen, } 1805\end{array}$ & + & + & + & - & $\mathrm{F}$ \\
\hline 5. & $\begin{array}{l}\text { Pienik wierzbowy } \\
\text { A. salicina Goeze, } 1778\end{array}$ & + & + & + & + & $\mathrm{F}$ \\
\hline III. & Skoczkowate - Cicadellidae & & & & & \\
\hline 6. & $\begin{array}{l}\text { Skoczek ziemniaczak } \\
\text { Empoasca solani }=\text { E. pteridis } \text { Curtis, } 1846\end{array}$ & + & - & - & - & $\mathrm{F}$ \\
\hline 7. & E. vitis Göthe, 1875 & + & - & - & - & $\mathrm{F}$ \\
\hline 8. & $\begin{array}{l}\text { Skoczek czarnoplamek } \\
\text { Eupteryx atropunctata Goeze, } 1778\end{array}$ & + & + & + & + & $\mathrm{F}$ \\
\hline 9. & $\begin{array}{l}\text { Skoczek sześciowek } \\
\text { Macrosteles laevis Ribaut, } 1927\end{array}$ & + & + & + & + & $\mathrm{F}$ \\
\hline IV. & Szydlakowate - Delphacidae & & & & & \\
\hline 10. & $\begin{array}{l}\text { Skoczek trawnik } \\
\text { Javesella pellucida Fabricius, } 1794\end{array}$ & + & + & + & + & $\mathrm{F}$ \\
\hline 11. & Laodelphax striatellus Fallén, 1826 & + & + & + & + & $\mathrm{F}$ \\
\hline C. & $\begin{array}{l}\text { Pluskwiaki różnoskrzydłe } \\
\text { Heteroptera }\end{array}$ & & & & & \\
\hline V. & Puklicowate - Acanthosomatidae & & & & & \\
\hline 12. & $\begin{array}{l}\text { Puklica rudnica } \\
\text { Acanthosoma haemorrhoidale Linnaeus, } 1758\end{array}$ & + & + & - & - & $\mathrm{F}$ \\
\hline VI. & Dzióbałkowate - Anthocoridae & & & & & \\
\hline 13. & $\begin{array}{l}\text { Dzióbałek gajowy } \\
\text { Anthocoris nemorum Linnaeus, } 1761\end{array}$ & + & + & + & + & $\mathrm{Z}$ \\
\hline 14. & $\begin{array}{l}\text { Dzióbałek mały } \\
\text { Orius minutus Linnaeus, } 1758\end{array}$ & + & + & + & + & $\mathrm{Z}$ \\
\hline 15. & O. niger Wolf, 1811 & + & - & + & + & $\mathrm{Z}$ \\
\hline VII. & Smukleńcowate - Beritidae & & & & & \\
\hline 16. & $\begin{array}{l}\text { Smukleniec komarnicowaty } \\
\text { Neides tipularius Linnaeus, } 1758\end{array}$ & + & + & + & + & $\mathrm{F}$ \\
\hline VIII. & Wtykowate - Coreidae & & & & & \\
\hline 17. & $\begin{array}{l}\text { Wtyk straszyk } \\
\text { Coreus marginatus Linneaus, } 1758\end{array}$ & + & + & + & - & $\mathrm{F}$ \\
\hline IX. & Zwińcowate - Lygaeidae & & & & & \\
\hline 18. & $\begin{array}{l}\text { Zwiniec rycerzyk } \\
\text { Lygaeus equestris Linnaeus, } 1758\end{array}$ & + & - & + & + & $\mathrm{F}$ \\
\hline $\mathrm{X}$. & Tasznikowate - Miridae & & & & & \\
\hline 19. & $\begin{array}{l}\text { Przegonik bezskrzydly } \\
\text { Halticus aptenus Linnaeus, } 1758\end{array}$ & - & - & + & - & $\mathrm{F}$ \\
\hline
\end{tabular}




\begin{tabular}{|c|c|c|c|c|c|c|}
\hline 1 & 2 & 3 & 4 & 5 & 6 & 7 \\
\hline 20. & $\begin{array}{l}\text { Zmienik ziemniaczak } \\
\text { Lygus pratensis Linnaeus, } 1758\end{array}$ & + & + & - & - & $\mathrm{F}$ \\
\hline 21. & $\begin{array}{l}\text { Zmienik lucernowiec } \\
\text { L. rugulipennis Poppius, } 1911\end{array}$ & + & + & + & + & $\mathrm{F}$ \\
\hline 22. & $\begin{array}{l}\text { Ścięga wędrowna } \\
\text { Notostira erratica Linnaeus, } 1758\end{array}$ & - & - & + & + & $\mathrm{F}$ \\
\hline 23. & N. elongata Geoffroy, 1785 & - & - & + & + & $\mathrm{F}$ \\
\hline 24. & $\begin{array}{l}\text { Zmienik złocieniowiec } \\
\text { Orthops campestris Linnaeus, } 1758\end{array}$ & + & + & + & + & $\mathrm{F}$ \\
\hline 25. & $\begin{array}{l}\text { Wysmukłek smugowany } \\
\text { Trigonotylus pulchellus Hahn, } 1834\end{array}$ & + & + & - & - & $\mathrm{F}$ \\
\hline 26. & $\begin{array}{l}\text { Wysmukłek paskorogi } \\
\text { Trigonotylus caelestialium Kirkaldy, } 1902\end{array}$ & + & + & + & - & $\mathrm{F}$ \\
\hline XI. & Zażartkowate - Nabidae & & & & & \\
\hline 27. & $\begin{array}{l}\text { Zażartka drzewna } \\
\text { Himacerus apterus Fabricius, } 1798\end{array}$ & + & + & - & + & $\mathrm{Z}$ \\
\hline 28. & $\begin{array}{l}\text { Zażartka pospolita } \\
\text { Nabis ferus Linnaeus, } 1758\end{array}$ & + & + & + & + & $\mathrm{Z}$ \\
\hline 29. & $\begin{array}{l}\text { Zażartka skąpowłosa } \\
\text { N. pseudoferus Remane, } 1949\end{array}$ & - & - & + & - & $\mathrm{Z}$ \\
\hline 30. & $\begin{array}{l}\text { Zażartka podtrawna } \\
\text { N. rugosus Linnaeus, } 1758\end{array}$ & + & + & + & + & $\mathrm{Z}$ \\
\hline XII. & Tarczówkowate - Pentatomidae & & & & & \\
\hline 31. & $\begin{array}{l}\text { Lednica zbożowa } \\
\text { Aelia acuminata Linnaeus, } 1758\end{array}$ & + & + & + & + & $\mathrm{F}$ \\
\hline 32. & $\begin{array}{l}\text { Plusknia jagodziak } \\
\text { Dolycoris baccarum Linnaeus, } 1758\end{array}$ & + & - & + & + & $\mathrm{F}$ \\
\hline 33. & $\begin{array}{l}\text { Strojnica baldaszówka } \\
\text { Graphosoma lineatum Linnaeus, } 1758\end{array}$ & + & + & - & - & $\mathrm{F}$ \\
\hline 34. & $\begin{array}{l}\text { Odorek zieleniak } \\
\text { Palomena prasina Linnaeus, } 1761\end{array}$ & + & + & + & - & $\mathrm{F}$ \\
\hline 35. & $\begin{array}{l}\text { Tarczówka rudonoga } \\
\text { Pentatoma rufipes Linnaeus, } 1758\end{array}$ & + & + & + & + & $\mathrm{F} / \mathrm{Z}$ \\
\hline 36. & $\begin{array}{l}\text { Zbrojec dwuzębny } \\
\text { Picromerus bidens Linnaeus, } 1758\end{array}$ & + & - & - & - & $\mathrm{Z}$ \\
\hline XIII. & Ziemikowate - Thyreocoridae & & & & & \\
\hline 37. & Thyreocoris scarabaeoides Linnaeus, 1758 & + & + & + & + & $\begin{array}{c}\mathrm{F} \\
\text { (imagines) }\end{array}$ \\
\hline
\end{tabular}

F - fitofag - phytophag, Z - zoofag - zoophag

+ występowanie gatunku - occurrence species

- brak gatunku - no species

gatunków pospolitych, polifagicznych. Żeruje na różnych roślinach uprawnych, a także na drzewach i w szkółkach, powodując znaczne szkody (Korcz 1994).

W grupie subdominantów w Suponinie stwierdzono 5 gatunków, a w Dobrczu 4. Najliczniej na obu stanowiskach notowano Laodelphax striatellus, $\mathrm{z}$ rodziny szydlakowatych. Jest to gatunek transpalearktyczny, polifagiczny rozpowszechniony na terenie naszego kraju (Nowacka 1996). W Suponinie, w grupie tej zanotowano także: zmiennika złocieniowca Orthops campestris (2,52\%), skoczka sześciorka Macrosteles laevis (2,39\%), ścięgę wędrowną Notostira erratica $(2,39 \%)$ i pienika wierzbowca Aphrophora salicina (2,25\%), a w Dobrczu obok L. striatellus $(3,30 \%)$ również pienika wierzbowca A. salicina (3,05\%), zmiennika lucernowca L. rugulipennis $(2,80 \%)$ i mszycę Cavariella aegopodii (2,29\%). Według Mrówczyńskiego i wsp. (2007) w ostatnich latach obserwuje się wzrost nasilenia występowania pieników, które w wyniku wysysania soków mogą powodować łamliwość pędów. Występowanie i szkodliwość tych pluskwiaków spowodowana jest wprowadzeniem monokultur i uproszczeniami w agrotechnice (brak podorywek i orek) oraz zmianami klimatycznymi. 
Tabela 2. Dominacja osobnicza [\%]

Table 2. Specimen dominance [\%]

\begin{tabular}{|c|c|c|c|c|}
\hline \multirow{3}{*}{$\begin{array}{c}\mathrm{D} \\
\text { Klasa dominacji } \\
\text { Dominanceclass }\end{array}$} & \multicolumn{4}{|c|}{ Stanowiska - Localisation } \\
\hline & \multicolumn{2}{|l|}{ Dobrcz } & \multicolumn{2}{|l|}{ Suponin } \\
\hline & nazwa gatunku - species name & {$[\%]$} & nazwa gatunku - species name & {$[\%]$} \\
\hline \multirow{2}{*}{$\begin{array}{c}\text { D5 } \\
>10 \%\end{array}$} & Skoczek trawnik Javesella pellucida & 40,92 & Skoczek trawnik Javesella pellucida & 43,37 \\
\hline & $\begin{array}{l}\text { Mszyca wierzbowa pospolita } \\
\text { Aphis farinosa }\end{array}$ & 22,36 & $\begin{array}{l}\text { Mszyca wierzbowa pospolita } \\
\text { Aphis farinosa }\end{array}$ & 20,03 \\
\hline $\begin{array}{c}\mathrm{D} 4 \\
5,1-10 \%\end{array}$ & Thyreocoris scarabaeoides & 5,10 & $\begin{array}{l}\text { Zmienik lucernowiec } \\
\text { Lygus rugulipennis }\end{array}$ & 5,70 \\
\hline \multirow{5}{*}{$\begin{array}{c}\text { D3 } \\
2,1-5,0 \%\end{array}$} & Laodelphax striatellus & 3,30 & Laodelphax striatellus & 4,11 \\
\hline & Pienik wierzbowy Aphrophora salicina & 3,05 & Zmienik złocieniowiec Orthops campestris & 2,52 \\
\hline & Zmienik lucernowiec Lygus rugulipennis & 2,80 & Skoczek sześciowek Macrosteles laevis & 2,39 \\
\hline & $\begin{array}{l}\text { Mszyca wierzbowo-marchwiana } \\
\text { Cavariella aegopodii }\end{array}$ & 2,29 & Ścięga wędrowna Notostira erratica & 2,39 \\
\hline & & & Pienik wierzbowy Aphrophora salicina & 2,25 \\
\hline \multirow{5}{*}{$\begin{array}{c}\mathrm{D} 2 \\
1,1-2,1 \%\end{array}$} & Cavariella pastinacae & 2,03 & $\begin{array}{l}\text { Mszyca wierzbowo-marchwiana } \\
\text { Cavariella aegopodii }\end{array}$ & 1,98 \\
\hline & Lednica zbożowa Aelia acuminata & 1,65 & Dzióbałek mały Orius minutus & 1,86 \\
\hline & $\begin{array}{l}\text { Smukleniec komarnicowaty } \\
\text { Neides tipularius }\end{array}$ & 1,52 & Lednica zbożowa Aelia acuminata & 1,86 \\
\hline & Skoczek sześciowek Macrosteles laevis & 1,40 & Thyreocoris scarabaeoides & 1,59 \\
\hline & Pienik olchowiec Aphrophora alni & 1,27 & Cavariella pastinacae & 1,33 \\
\hline $\begin{array}{c}\mathrm{D} 1 \\
0,1-1,1 \%\end{array}$ & pozostałe gatunki - other species & & pozostałe gatunki - other species & \\
\hline
\end{tabular}

D5 - eudominanty, D4 - dominanty, D3 - subdominanty, D2 - recedenty, D1 - subrecedenty

D5 - eudominats, D4 - dominants, D3 - subdominants, D2 - recedents, D1 - subrecedents

Pozostałe gatunki pluskwiaków wystapiły mniej licznie (poniżej 2,1\%) i nie stanowiły istotnego zagrożenia dla wierzby.

\section{Wnioski / Conclusions}

1. Na wierzbie wiciowej $S$. viminalis stwierdzono występowanie pluskwiaków, należących do 3 podrzędów: Sternorrhyncha, Auchenorhyncha, Heteroptera oraz 13 rodzin: Aphididae, Aphrophoridae, Cicadellidae,
Delphacidae, Acanthosomatidae, Anthocoridae, Beritidae, Coreidae, Lygaeidae, Miridae, Nabidae, Pentatomidae i Thyreocoridae.

2. Ogółem zebrano 37 gatunków pluskwiaków: w Dobrczu - 33, a w Suponinie - 30 .

3. W badanych stanowiskach w grupie subdominantów stwierdzono występowanie skoczka trawnika $J$. pellucida Fab. i mszycy wierzbowej A. farinosa Gmelin.

4. W Suponinie gatunkiem dominującym był zmiennik lucernowiec L. rugulipennis Popp., a w Dobrczu - T. scarabaeoides L.

\section{Literatura / References}

Fauna Europaea 2011. Fauna Europaea version 2.4. Web Service available online at http://www.faunaeur.org, accessed: 2011.

Kasprzak K., Niedbała W. 1981. Wskaźniki biocenotyczne stosowane przy porządkowaniu i analizie danych w badaniach ilościowych. s. 397-416. W: „Metody Stosowane w Zoologii Gleby” (M. Górny, L. Grum, red.). PWN, Warszawa, 483 ss.

Korcz A. 1994. Szkodliwe pluskwiaki z rzędu różnoskrzydłych (Heteroptera). T. 1. s. 233-292. W: „Diagnostyka Szkodników Roślin i ich Wrogów Naturalnych" (J. Boczek, red.). SGGW, Warszawa, 328 ss.

Lis J.A. 1997. Klucze do oznaczania owadów Polski, cz. XVIII. Pluskwiaki różnoskrzydłe - Heteroptera, z. 12, Plataspidae, Thyreocoridae i Cydnidae. Oficyna Wydawnicza TURPRESS, Toruń, 29 ss.

Lis J.A. 2000. Klucze do oznaczania owadów Polski, cz. XVIII. Pluskwiaki różnoskrzydłe - Heteroptera, z. 14, Tarczówkowate Pentatomidae. Polskie Towarzystwo Entomologiczne, Toruń, 76 ss. 
Mrówczyśki M., Nijak K., Pruszyński G., Wachowiak H. 2007. Zagrożenie roślin energetycznych przez szkodniki. Prog. Plant Prot./Post. Ochr. Roślin 47 (4): 347-350.

Nowacka W. 1996. Uproszczony klucz do oznaczania wybranych gatunków piewików (Auchenorrhyncha) występujących na uprawach roślinnych. T. 3. s. 103-138. W: „Diagnostyka Szkodników Roślin i ich Wrogów Naturalnych” (J. Boczek, red.). SGGW, Warszawa, 385 ss.

Tomczyk A. 2008. Intensywność fotosyntezy i przyrost biomasy wierzby energetycznej uszkodzonej przez szkodniki. Post. Nauk Rol. 4-5: 47-54.

Wrzesińska D., Wawrzyniak M. 2011. Chrząszcze (Coleoptera) spotykane na plantacjach wierzby wiciowej (Salix vinimalis). Prog. Plant Prot./Post. Ochr. Roślin 51 (1): 248-251.

Wrzesińska D., Wawrzyniak M. 2012. Motyle (Lepidoptera) zasiedlające plantacje wierzby wiciowej (Salix viminalis). Prog. Plant Prot./Post. Ochr. Roślin 52 (2): 248-251. 